(i-COME'20)

INTERNATIONAL CONFERENCE ON COMMUNICATION AND MEDIA 2020

\title{
POLITICAL INFORMATION EFFICACY AND SENSE-MAKING PROCESS: “STRUCTURAL EQUATION MODELLING” (SEM) APPROACH
}

\author{
Suhaimee Saahar Saabar (a)* \\ *Corresponding author \\ (a) Faculty of Communication and Media Studies, UiTM, 40450, Shah Alam, Malaysia, \\ suhaimee@salam.uitm.edu.my
}

\begin{abstract}
By delivering useful facts to the target demographic, political ads play a major role during election campaigns. The purpose of this research is to examine the impact of political ads on the effectiveness of political knowledge among young voters. To consider youth voters segment, Kaid developed the idea of political information efficacy; participation in the electoral process. Meanwhile, at the same point, the engagement of young voters in the democratic process has become an important topic for the communication scholars to understand the influence of mass media toward young voters, especially in developing countries such as Malaysia. This research, therefore, analysed the impact of political ads on 374 young voters in DUN Kota Damansara, in order to understand their political knowledge effectiveness by concentrating on the internal efficacy component and the decision-making phase. Additionally, the data was analysed by PLS-SEM to build a structural model of the study. Latent variables were constructed based on the literature reviews identified such as: (1) political information efficacy, (2) information needs, (3) information use, (4) political disaffection/gap and (5) voting decision. The findings find that political information efficacy can be a strong predictor.
\end{abstract}

2357-1330 C 2021 Published by European Publisher.

Keywords: Political advertising, political information efficacy, sensemaking, young voters 


\section{Introduction}

In the last 14th general election (2018) there are approximately 1.6 million of eligible and firsttime voters were registered. They have become the key focus target for political parties to engage with them by affecting their political efficacy and engaging them in the electoral process where their decision has changed the country's political situation and conditions (Febriansyah \& Ismail, 2013). In any democratic countries, the role of young generation plays a significant function and also will determine the political direction of this nation. Their involvement in the last election has a significant role in determine the election results. Most of the Malaysian young voters have decided not to vote Barisan Nasional and decided to vote for Pakatan Harapan to form the new government. The results were eye shocking and the domination of $\mathrm{BN}$ has been denied.

Since 1980s most of the scholars are interested to study this segment of voters. Therefore, study to consider the variables that affect the perceptions and actions of young voters is important since it is a daunting challenge to inspire them (Muralidharan \& Sung, 2016). The challenges such as low level of political participation and confidence, lack of knowledge and experience and easily to be influence has become part of the main challenges for scholars to explore (Saabar, 2014; Lin \& Lim, 2002). Meanwhile, GE 14th has proven it differently where there are several factors that shape and influence their decision making. At the same time, political advertising campaigns played a significant role where most of the political information and messages were disseminated in different shapes and kinds with different medium. The most significant aspect, however, is how information was used by voters and guide them to make their decision.

During a political campaign, political parties will design their political information in different shapes and forms. The shapes can be in the form such as debates, posters, placard, stickers, flags and many more. As an example, debate is one of the most important sources of information during election campaigns. Meanwhile, some recent studies have found that beside debates, the exposure of political advertisements in different formats and styles has affected voters' knowledge, involvement, participation, efficacy and disaffection (Chou, 2014). Scholars believe that exposure to political advertising messages will have some significant effects especially the amount of information received by the voters (Sharma, 2012). In fact, such disclosures will also affect the voter's assessment of candidates and political processes that occurred during that time.

Thus, scholars believe that political advertising can have its own impact on voters. This can be seen in some forms such as in the form of knowledge, participation, involvement, efficacy, cynicism, information retrieval and decision of voters. Political ads influence the motivation of voters to seek information, that affect their involvement and political participation, according to Freedman et al. (2008). Thus, to be an informed voter, citizens shall use their rationale thinking to make their decision based on information, knowledge and efficacy (Stevens, 2005). 


\section{Problem Statement}

The political landscape in Malaysia has reformed. Before 14th General Election, several important issues such as BERSIH, 1MDB, GST, RM2.6 billion, cost of living, unemployment and oil price had influenced Malaysian voters' in terms of their candidates' selection, issues understanding, and perception on parties especially towards Barisan Nasional (Noordin et al., 2010; Ismail et al., 2013 ). At the same time, political tsunami is the term given by Malaysian scholars to describe the changes in Malaysian politics since 2008, 'Chinese Tsunami' (Abdillah, 2014: Welsh, 2013). The election results have found to be a new challenge for BN to remain their political hegemony. The winning of Pakatan Harapan (PH) has affected Malaysian political landscape with what they called as Malaysia Baharu (New Malaysia). All these factors have strongly affected young voters' behaviour. Their political efficacy, their needs for political information, and their sense of personal efficacy may vary, all of which have a significant impact on their voting attitudes. In this case, certain situational factors would be the key predictor for assessing the political information efficacy of young voters, and the needs and the use of political information. Therefore, this paper attempts to examine at the impact of political ads messages on young voters' behaviour. This paper also tries to explain what kinds of political knowledge the young voter needs to make decision. Political advertising serves as source of information not only promoting the candidates but some political offers through their political manifesto purposely created to persuade and influence voters' mind and behavior (Diagnault et al., 2012; Kaid et al., 2007). Based on previous elections, most of political parties will fully utilized political advertising as the main political communication tools. Previous studies show that exposure to political ads can influence the way voters retain political knowledge such as information about party position on certain issues, issues on candidates or image attributes.

\section{Research Questions}

- What are the effects of political advertising messages on young voters' political decision?

- What are the factors that determine the political disaffection on young voters' decision?

\section{Purpose of the Study}

The main purpose of this paper is to explore the effects of political ads exposure on voters' political decision by examining the factor such as political information efficacy, sense-making, political situation and political disaffection. A first way of calculating any changes is by developing a specific measurement of political sense efficacy and information named Political Advertising Sense Efficacy. This latest measurement would be useful to the academic community and will guide and assist in defining truly valuable sources of political information.

\section{Research Methods}

For the purpose of this study, survey was selected as the main method to collect the data. Most of political communication analysis is heavily depend on survey as one of the dominant methodological 
tools. Study on political ads has introduced various types of analysis in methodology of survey, focusing on several observational results. The selection of this method is based on several factors such as cost, suitability and also sample selection based on the purpose of the study.

\subsection{Sampling}

To determine the size of the sample was based on proportional stratified sampling. The two main goals are because respondents can be categorized based on characteristics such as race, gender, social class, age and gender. For this purpose of the study, 374 samples were chosen in DUN Kota Damansara. The samples were registered voters. The samples then were divided into different categories which are based on race, age and gender.

\subsection{Sample size}

PLS-SEM was used in this study. Therefore, the minimum sample size for PLS-SEM that has been determined has been followed to ensure it meets the requirement of the assessment.

The requirement has been defined by Hair et al. (2014). However, larger sample size is optimal for better interpretation (Field, 2013). There are five factors need to be weight to for us to conduct a statistical power analysis, (1) significance level or criterion; (2) effect size; (3) desired power ; (4) estimated variance and (5) sample size.

\subsection{Develop research structural model}

The next step is to build a structural model of the study. It is a diagram illustrates the hypothesis of the study that display the relationship of each variable to be examined (Hair et al., 2014). The diagram is referring as a path model. It shows all the connection of all the variables/constructs based on the theory and logic that visually displayed in research hypotheses that will be tested. Two elements need to be tested in the path models which are the structural model and measurement model. The relationship and the measurement among the latent variables in this study is described by the structural model developed in this study. Latent variables were constructed based on the literature reviews identified such as:

- political information efficacy,

- information needs,

- information use,

- political disaffection/gap and

- voting decision.

Furthermore, this study will test the hypothesis formed by using the measurements that have been selected in this study. 


\section{Findings}

The data collection and analysis process are an important part of testing the hypothesis in this study. It will determine and decide the direction and quality of a study. To ensure that all these are qualified, some basic tests such as identifying data normality, outliers, have been tested and resolved. All the instruments in this study have been tested for their validity. The study was conducted for 100 days from March until May 2017. A total of four hundred questionnaires were issued, and for data processing only 374 questionnaires were usable. After some data cleaning process, 374 questionnaires were qualified to be used for the structural model analysis. A total of four hundred questionnaires were issued, and for data processing only 374 questionnaires were usable. The benefits of utilising SmartPLS 3.0 are that limited samples and dynamic models can be used easily.

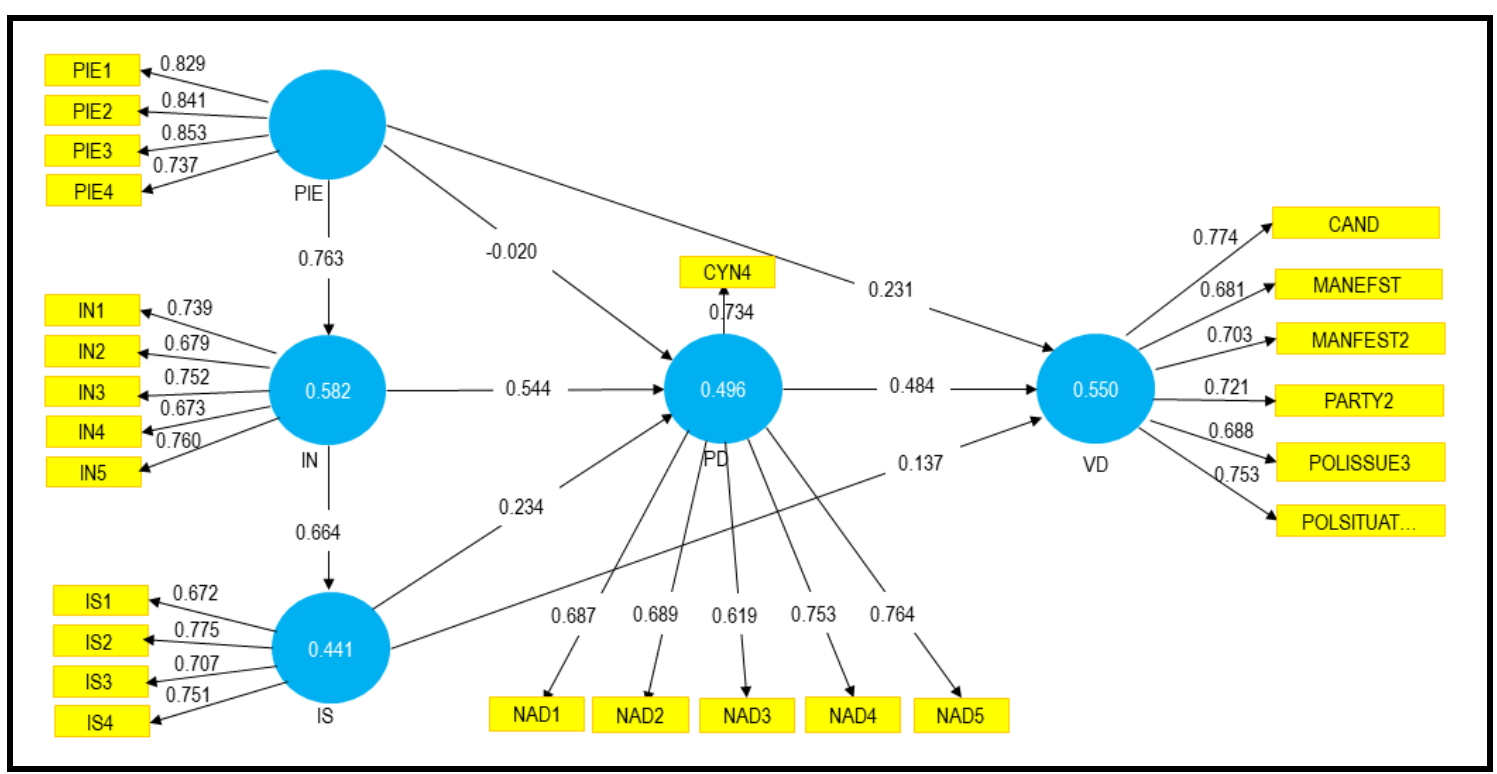

Figure 1. Structural Model

Note: PIE, IN and IS are dimensions for SENSE-MAKING. In PLS-SEM they are depicted as the first-order constructs and Political Disaffection as higher-order construct. These three dimensions will be omitted in the Structural Model. The assessment of Structural Model will use latent variable scores generated from this Measurement Model. This method is known as the Two-Stage Approach Assessing Hierarchical Latent Variable Model (Becker et al., 2012)

H1 Is there a relationship between PIE and IN?

$\mathrm{H} 2$ Is there a relationship between IN and IS?

H3 Is there a relationship between PIE and GAP?

H4 Is there is a relationship between IS and GAP?

H5 Is there a relationship between GAP and VD?

Figure 1 shows the structural model developed in this study. There are five main constructs were tested in this structural mode to test the relationship between constructs.

Table 1. Path co-efficient assessment

\begin{tabular}{lcccccc}
\hline & $\begin{array}{c}\text { Original } \\
\text { Sample (O) }\end{array}$ & $\begin{array}{c}\text { Sample Mean } \\
(\mathbf{M})\end{array}$ & $\begin{array}{c}\text { Standard } \\
\text { Deviation } \\
\text { (STDEV) }\end{array}$ & $\begin{array}{c}\text { T Statistics } \\
(\mid \mathbf{O} / \text { STDEV|) }\end{array}$ & P Values & Result \\
\hline H1 PIE -> IN & 0.763 & 0.763 & 0.026 & 29.442 & 0.000 & significant
\end{tabular}




\begin{tabular}{ccccccc} 
H2 IN -> IS & 0.664 & 0.665 & 0.032 & 20.53 & 0.000 & significant \\
H3 PIE -> & -0.02 & -0.022 & 0.07 & 0.287 & 0.775 & Not significant \\
GAP & & & & & \\
$\begin{array}{c}\text { H4 IS -> GAP } \\
\text { H5 GAP -> }\end{array}$ & 0.234 & 0.237 & 0.057 & 4.101 & 0.000 & significant \\
VD & 0.484 & 0.486 & 0.051 & 9.591 & 0.00 & significant \\
\hline
\end{tabular}

Table 1 shows the result of path co-efficient assessment in this study. There are five latent constructs in the overall structural model, namely, i) political information efficacy, ii) information needs, iii) information seeking, (iv) political disaffection and (v) voting decision. From five hypotheses developed in this study there only one is not significant and four are significant.

\section{Conclusion}

Based on figure 1 and table 1, the findings show that most hypotheses meet the results of the study. Of the five hypotheses formed, only one hypothesis was found to be insignificant. There is a a significant relationship between PIE and IN. This hypothesis is supportive political information efficacy (PIE) where low levels of information efficacy have an impact on political knowledge. It may affect young people from voting in an election. In second hypothesis, there is a significant relationship between Information Needs and Information Seeking. This supports the argument that if voters do not have adequate information and knowledge, it will affect the political decision process, especially in their search for information. Meanwhile in the third hypotheses, there is insignificant relationship between political information and gap, it means that if voters feel their information need not fully fulfil, they will not satisfy with their political efficacy and it will affect their political disaffection. For fourth hypotheses, there is significant relationship between information seeking and gap, if the voters find that there is a lack of political information especially on candidates, parties, manifesto, political issues they are capable of affecting the decisions they will make later. Thus, incomplete decision will arise in this relationship. Yang et al. (2014) emphasised that when respondents believe they must be informed of an issue, they would generally pursue more details to overcome their uncertainty.

The findings find that political information efficacy can be a strong predictor. Based on the results of the study and some previous studies, PIE has a strong prediction on information needs, information seeking and political decision making. The study also found that young voters in this study have strong feel of political efficacy or confidence in their ability to participate in politics process after having been exposed with political advertisement advertised by political parties during election campaign. The process of sense-making can also act as a strong predictor that seen to have a viable factor of information seeking for voter to acquire political information. The findings reveal that media exposure especially social media affects the information efficacy of this specific group. In this modern world, the influence of information communication technology and social media influence the construction of political messages in the form of political ad with the desired format and effect. Political advertisements play an important role in influencing voter information seeking and at the same time it also affects the political efficacy of these young people. 
Political advertising lets people grasp the stuff happening around them. Political advertisements have a substantial association with the effectiveness of political information efficacy. Studies also shown that if internal efficacy is strong, it can affect the efficacy of political knowledge, either in recognising a problem or making it an involved voter in the political process. As a medium of political persuasion, political advertisements are used by political parties to influence voters' internal efficacy and thus influence the process of sense-making, especially in the pursuit for information and achieve their information needs.

This analysis is confined to the construction of political ads sense efficacy structured model. Therefore, by including a wider group of respondents from various locations, more studies are suggested, DUN and Parliament. The resulting structured model can be seen as an initial analysis to learn more about the processing of knowledge by voters affecting other variables. The construction of political ads sense efficacy structured modelling is expected to assist and can be used as a guide in understanding voters' political behaviour.

This study only involves some latent factors in building political ads sense efficacy structured modelling. Hence, it is proposed that further studies involve other latent factors to enrich the study. In addition to the latent factors used, there are other factors that can affect young voters' attitude and behaviour in line with current developments either from political information efficacy constructs or sensemaking constructs.

\section{References}

Abdillah Noh. (2014). Malaysia 13th General Election: A short note on Malaysia's continuing battle with ethnic politics. Electoral Studies, 34, 266-269.

Becker, J. M., Klein, K., \& Wetzels, M. (2012). Hierarchical latent variable models in PLS-SEM: guidelines for using reflective-formative type models. Long range planning, 45(5-6), 359-394.

Chou, H. Y. (2014). Effects of endorser types in political endorsement advertising. International Journal of Advertising, 33(2).

Diagnault, P., Soroka, S. N., \& Giasson, T. (2012). The Perception of Political Advertising During An Election Campaign: A Preliminary Study of Cognitive and Emotional Effects. Canadian Journal of Communication, 38(2013), 167-186.

Febriansyah, M., \& Ismail, M.K. (2013). Partisipasi Anak Muda Dalam Politik Baru Di Malaysia. Kertas Kerja Yang Dibentangkan Dalam Simposium Kebudayaan Indonesia Malaysia (SKIM), 12-14 November 2013 Di Universitas Padjajaran, Bandung, Indonesia., 53(November), 1689-1699.

Field, A. (2013). Discovering Statitstics Using IBM SPSS Statistics (4th ed.). Los Angeles: Sage Publication.

Freedman, P., Franz, M., \& Goldstein, K. (2008). Campaign Advertising and Democratic Citizenship. American Journal of Political Science, 48(4), 723-741.

Hair, J. F. J., Hult, G. T. M., Ringle, C., \& Sarstedt, M. (2014). A Primer on Partial Least Squares Structural Equation Modeling (PLS-SEM). Long Range Planning, 46.

Ismail, S., Siti Zabedah, S., Shira Haniza, Y., \& Azli, M. (2013). Influence of Political Issues, Media and Personality Traits on Voting Trend. International Proceedings of Economics Development and Research, 64(17), 79-83.

Kaid, L. L., McKinney, M. S., \& Tedesco, J. C. (2007). Introduction: Political Information Efficacy and Young Voters. American Behavioral Scientist, 50(9), 1093-1111.

Lin, Y., \& Lim, S. (2002). Relationships of media use to political cynicism and efficacy: A preliminary study of young South Korean voters. Asian Journal of Communication, 12(1), 25-39. https://doi.org/10.1080/01292980209364812 
Muralidharan, S., \& Sung, Y. (2016). Direct and Mediating Effects of Information Efficacy on Voting Behavior: Political Socialization of Young Adults in the 2012 U.S. Presidential Election. Communication Reports, 29(2), 100-114.

Noordin, N. M. Z. H., Mohamed Sawal, S., Ibrahim, Z. H., Hussin, Z., Zakaria, \& Nordin, J. (2010). "Malaysian young voters voices: Make or break political development?," 2010 International Conference on Science and Social Research (CSSR 2010), Kuala Lumpur, Malaysia, 2010, pp. 426-430. https://doi.org/10.1109/CSSR.2010.5773813

Saabar, S. S. @. (2014). A Survey on Young Voters Trust towards the Campaign of Janji Ditepati before 13th General Election. Procedia - Social and Behavioral Sciences, 155(October), 442-447. https://doi.org/10.1016/j.sbspro.2014.10.319

Sharma, K. (2012). Political Advertising and Voting Behaviour in India: The Mediating Role of Voting Decision Involvement. GSTF Journal of Law and Social Sciences, 1(1).

Stevens, D. (2005). Separate and Unequal Effects: Information, Political Sophistication and Negative Advertising in American Elections. Political Research Quarterly, 58(3), 413-425.

Welsh, B. (2013). Malaysia's Elections: A Step Backward. Journal of Democracy, 24(4), 136-150.

Yang, Z. J., Kahlor, L., \& Li, H. (2014). A United States-China Comparison of Risk Information-Seeking Intentions. Communication Research, 41(7), 935 -960. 